\title{
Calculation of thermal stress-strain state of soil base under the building on permafrost soil
}

\author{
Mikhail Rabinovich* \\ Moscow State University of Civil Engineering, Yaroslavskoe shosse, 26, Moscow, 129337, Russia
}

\begin{abstract}
Article presents problem statement and solution for joint calculation of temperature regime and stress-strain state of permafrost soils under building footing, with consideration of thermal impact from onsurface and buried high-temperature utilities. Based on a series of optimization tasks, a design model for stress-strain state has been developed, solutions of test problems have been obtained and analyzed to determine the degree of influence of temperature stresses and relation of the deformation characteristics of frozen soil in the negative temperature spectrum on the stress distribution and settlement values of frozen soil base under the building.
\end{abstract}

\section{Introduction}

Thermal stress-strain state calculation of heterogeneous soil bases with account for cryogenic processes is an important and complex task, that does not currently have common and rigorous solution. At the same time, there are a large number of publications on the theory of thermal conductivity and its technical applications in relation to permafrost soils [1-6].

The problem of predicting the temperature regime of defrosting and frosting soils was historically distinguished into two directions: creation of approximate engineering evaluation formulas and solution for the Stefan's problem. As a rule, in most approaches it is assumed that the thermal conductivity coefficient and the volumetric heat capacity of the medium change abruptly at freezing and defrosting points. Such change in thermophysical properties greatly complicates application of numerical methods to solve thermal conductivity problems with a phase transition. Numerical approach to solution of this type of problems is greatly facilitated by using "enthalpy-heat flow" method.

The largest number of developed and used models to calculate stress-strain state of soil base relies on the assumption of linear soils deformability principle being used. However, several researchers have developed proposals for specific mathematical models of soils in a nonlinear and elastic-plastic formulation [1,5-9]. However, relying only on linear operation of soil bases in many practical cases can give a good convergence of the calculation results with field observation data.

\footnotetext{
Corresponding author: $\underline{\text { RabinovichMV@mgsu.ru }}$
} 
The complexity and uniqueness of each specific task lies in the fact that it requires a certain stock of various algorithms that simulate different factors of a real physical process in order to be able to choose the most suitable option. Majority of mechanical tasks to study soil base state of structures in cryolitic zone are devoted to the study of stress-strain state of soils under assumption that the temperature regime determines the boundary between defrosted and frosted zones. Within each of these zones, it is considered that mechanical properties of the soils remain unchanged.

Considering dependence of deformational and strength characteristics of frozen soils on the temperature in the negative temperature spectrum, presents the task to develop a unified methodology for joint and interconnected calculation of the temperature regime and stressstrain state of soil base. Such approach to the calculation of soil bases was implemented by several researchers, among them N.I. Demin, Ya.A. Kronik, S.B. Ukhov, M.G. Mnushkin [8-10] and others.

This paper states a task to develop uniform methodology for calculation of thermal stress-strain state of frozen soil base under building and structures, with consideration of additional factors and nonlinear relation of deformability of frozen soil in the spectrum of negative temperatures. Using provisions of the classical theory of thermoelasticity for calculating the stress strain state of soil bases in the Far North, proposed and developed in the works $[7,11]$, should be considered as a first approximation in direction to solve this complex problem.

\section{Methods}

Calculation of thermal stress-strain state of soil bases relying on the equations of mathematical theory of elasticity and thermoelasticity of a linearly deformable half-space and nonlinear mechanics of frozen soils is another approximation to the real model of frozen soils, considering the cryogenic processes occurring in them. At the same time, complete deformation of the frozen soil consists of the deformation of the frozen thawing soil and deformation of defrosted soil under the influence of imposed load, thermal deformations, thawing deformations, rheological component of the deformation, including deformation of the frozen soil under the influence of the imposed load after its thawing.

A joint consideration of non-stationary temperature regime and stress-strain state of soil base composed of frozen soils, reveals zones where soil, depending on the thermal (atmospheric and technogenic) effects, changes from frozen to thawed state. The numerical value of thawing settlement is determined on the basis of the proposal by N.A. Tsytovich $[7,12]$ that during the thawing of frozen soil, thawing deformations occur, causing a vertical settlement of its surface according to the equation

$$
\mathrm{S}_{\mathrm{tw}}=\mathrm{A}_{\mathrm{o}} \cdot \mathrm{h}_{\mathrm{tw}}+\mathrm{a}_{\mathrm{o}} \cdot \mathrm{G} \cdot \mathrm{h}_{\mathrm{tw}}
$$

where: $\mathrm{S}_{\mathrm{tw}}$ - thawing settlement; $\mathrm{A}_{0}$ - thawing coefficient; $\mathrm{h}_{\mathrm{tw}}$ - thawing layer thickness; $\mathrm{a}_{\mathrm{o}}$ - compression index of thawed layer; $\mathrm{G}$ - vertical normal stresses.

The first summand in the calculations is factored in an explicit form, the second - is included in the settlement of the thawed soil under the influence of the imposed load.

Possible deformations arising during the thawing of frozen soil are determined experimentally as a thawing settlement under the "hot stamp" of the soil, and, therefore, takes into account not only the vertical displacement during thawing, but also possible horizontal deformations of limited lateral expansion. In other words, the defrosting ratio of frozen soil is an effective characteristic resulting in all of its possible deformations during thawing under local load. The depth of thawing $h_{t w}$ is determined excluding the depth of the active layer, thawing settlement of which is not factored in the calculations. 
Mechanical properties of frozen soil depend not only on its phase state, but also vary in the spectrum of negative temperatures. In the physical model of the soil used, the model of the total deformation of frozen soil non-linearly depends on its temperature. The nature of this dependence for studied soils was discovered based on the analysis of test data conducted in different years by Aksenov V.I., Karpunina V.I., Kronik Ya.A. and others [3, 13-15].

Necessity to consider temperature change on the stress strain state directly follows from numerous studies and observations of the temperature regime of soil bases, deformations of buildings and structures and changes in the load-carrying capacity of their foundations [1621].

\section{Results}

Series of optimization problems for calculation of thermal stress-strain state of frozen soil base have been formulated and solved to evidentiate degree of influence of temperature deformations and to factor in relation of temperature and deformation modulus of the soil on distribution of stresses and strains. Design diagram taken for the basis of the calculation (Fig. 1) (1 - buried high temperature collector; 2 - on-surface heat supply system; 3 - edge of the nominal foundation; 4 - border between soils of various genesis 5 - lower boundary of the compressible strata) tied to an apartment building in the Sinegorye village, Magadan region.

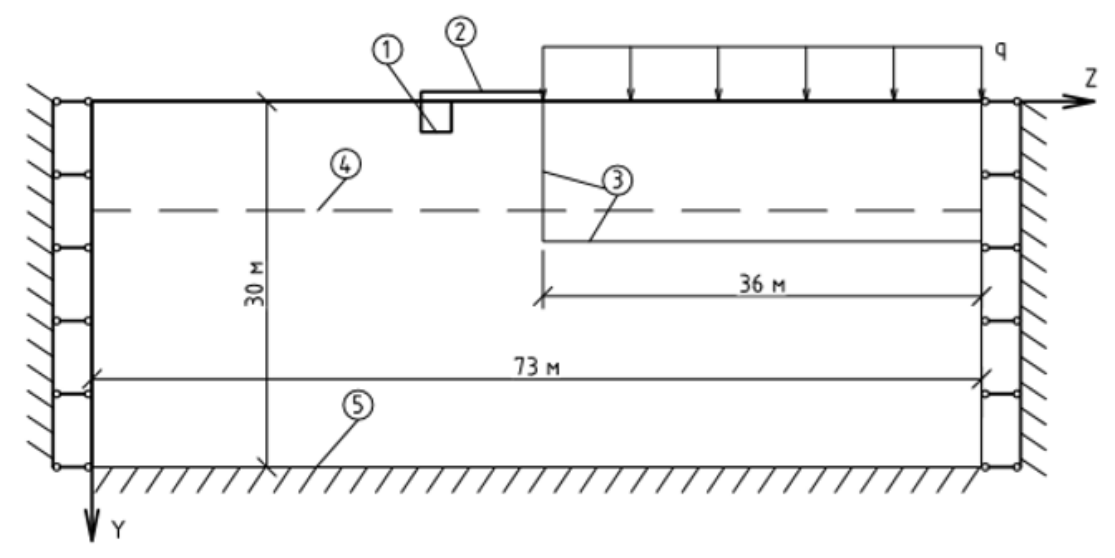

Fig. 1. Design diagram for the task of stress-strain state prognosis of the building permafrost soil base.

In order to identify the degree of influence of temperature stresses and to factor in relation of the deformation modulus $\mathrm{E}_{0}$ to temperature, a series of problems to calculate thermal stress-strain state of the frozen soil base of the building, with consideration of the temperature factor.

In Fig. 2 ( 1 - buried high temperature collector; 2 - on-surface heat supply system; 3 building; 4 - border between soils of various genesis 5 - lower boundary of the compressible strata; 6 - upper border of the permafrost soil; 7 - edge of the nominal foundation) and 3 (legend see in Fig. 2.) the isolines of the tangential stresses $\tau_{\mathrm{yz}}(\mathrm{kPa})$ and vertical normal stresses $\mathrm{G}_{\mathrm{y}}(\mathrm{kPa})$ are shown. 


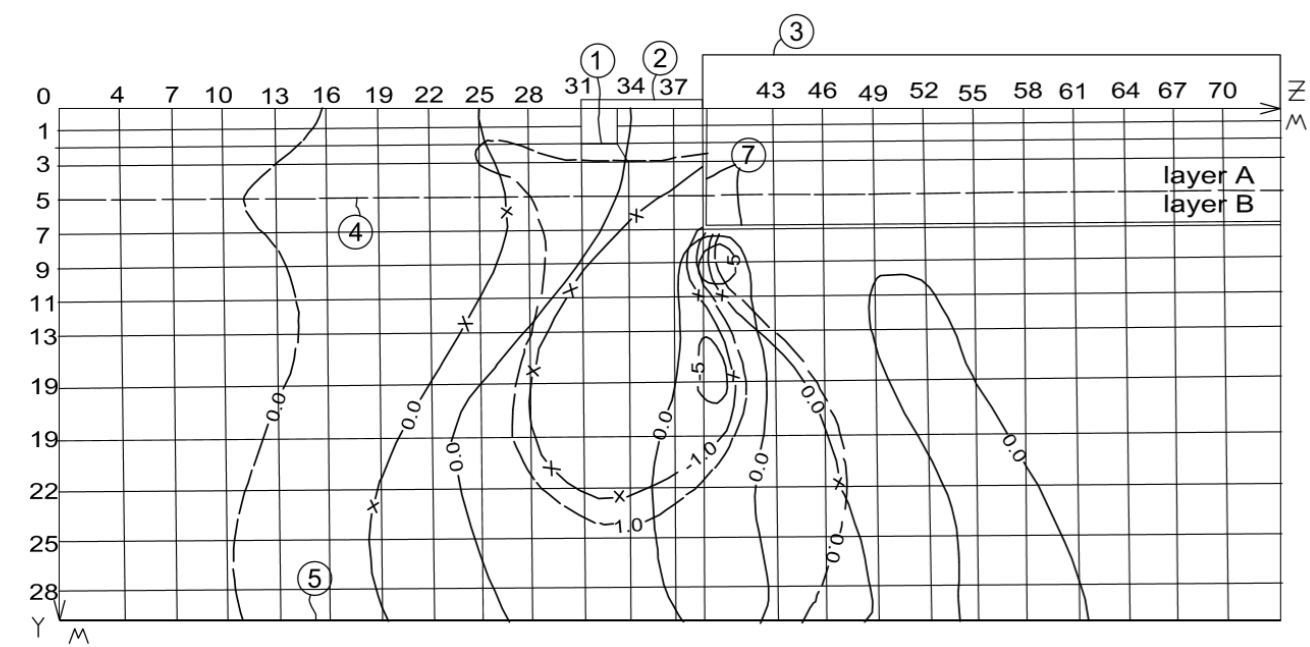

Fig. 2. Distribution of tangential stresses $\tau_{\mathrm{yz}}[\mathrm{kPa}]$ in the array of frozen soil base at a quasi-stable temperature regime according to the data of numerical calculations:

--- $x$--- without factoring thermal stresses and $E_{0} \neq f(t)$;

- - - - factoring temperature stresses and $\mathrm{E}_{0} \neq \mathrm{f}(\mathrm{t})$;

------- factoring temperature stresses and $\mathrm{E}_{0}=\mathrm{f}(\mathrm{t})$.

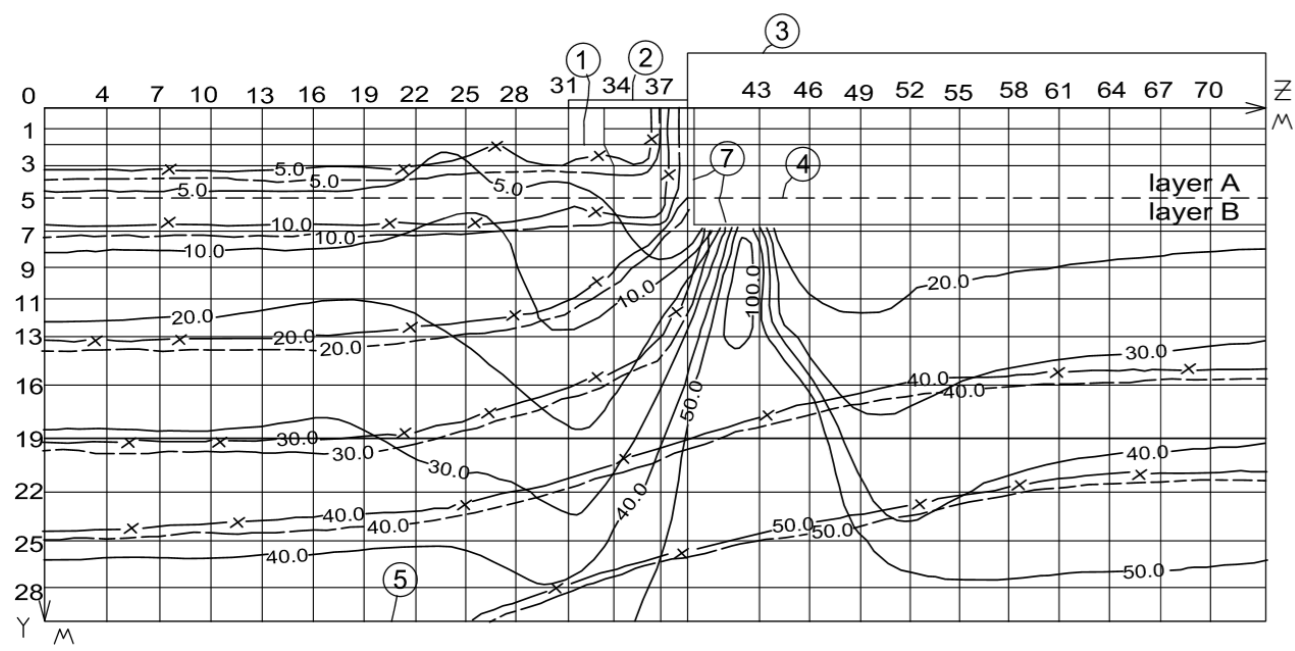

Fig. 3. Distribution of vertical normal stresses $\mathrm{G}_{\mathrm{y}}[\mathrm{kPa}]$ in the array of frozen soil base at a quasi-stable temperature regime according to numerical calculations.

\section{Discussion}

Factoring in the effect of temperature stresses led to a noticeable change in the pattern of stress distribution only for horizontal normal stresses Gy (Fig. 3) in the upper layers of the soil base (up to a depth of $19 \mathrm{~m}$ ), where a significant temperature gradient occurs. So, the zero stress isolines during thermal stresses placed deeper from $1 \mathrm{~m}$ to $5 \mathrm{~m}$ or more, and the isoline corresponding to $5 \mathrm{kPa}$ drops from $7 \ldots 8 \mathrm{~m}$ to $11 \ldots 12 \mathrm{~m}$ from the ground surface. Particularly noteworthy is the fact that factoring in the development of thermal stresses and strains when calculating thermal stress-strain state leads to a sign reversal of tangential stresses in a total of $40 \%$ of the calculated array. 
More significant changes occur in the thermal stress-strain state pattern of the calculated array of the frozen soil base, when factoring in not only thermal stresses and strains, but also the temperature and the deformation modulus Eo relation. When calculating the quasistable temperature distribution for December, the sign reversal zone of tangential stresses becomes more extensive (about $70 \%$ of the computational area), and a significant part of it extends between the building and the buried collector and directly under the building to the entire depth of the calculated array. Under the edge of the building tangential stresses changed from $+1.3 \mathrm{kPa}$, when only factoring temperature stresses, to $-11.3 \mathrm{kPa}$, when factoring relation of $\mathrm{E}_{0}$ with the temperature of the soil. In general, a more heterogeneous distribution of tangential stresses has been formed with frequent changes in the direction of the resulting stresses.

Extreme tangential stress of soil (Fig. 2) base under study is text $=10.85 \mathrm{kPa}$, and calculated tangential stresses arising in the soil under the edge of the nominal foundation reach $11.3 \mathrm{kPa}$, and a zone of plastic deformations is formed here. For a problem with a quasi-stable temperature regime, the zone of plastic deformations extends to a depth of 2.3 meters below the footing of the nominal foundation.

For normal stresses, factoring in relation between the deformation modulus and temperature leads to a significant redistribution of the calculated normal stresses $G_{y}$ at the base below the edge of the building. The nature of the stress distribution in the central part of the calculated array has changed. An area of high concentration of normal stress appeared (Fig. 3). Thus, at $5 \mathrm{~m}$ from the point with the maximum $\mathrm{G}_{\mathrm{y}}=137.7 \mathrm{kPa}$, a zone with tensile vertical normal stresses appeared $\left(\mathrm{G}_{\mathrm{y}}=-4.2 \mathrm{kPa}\right)$.

At a distance of $3 . .6 \mathrm{~m}$ from the edge of the buried stamp at a depth of $15 \mathrm{~m}$ from the ground surface, a zone of increased concentration of main normal stresses formed, their values exceed $100 \mathrm{kPa}$, and at certain points the maximum values reach $138 \mathrm{kPa}$, whereas in tasks without factoring Eo relation from the temperature, the main normal stresses, the values of which exceeded $50 \mathrm{kPa}$, occurred only at a depth of $22 \mathrm{~m}$ and more. Maximum main normal stresses, calculated without factoring relation between $E_{\text {s }}$ and temperature, reach only $62 \mathrm{kPa}$, and factoring of thermal stresses and relation between $E_{\text {s }}$ and temperature leads to an increase in these stresses under the building. Thus, the maximum main stress isoline is $30 \mathrm{kPa}$ without consideration of the temperature factor at a depth of $9 . .10 \mathrm{~m}$, and with consideration - $13 \ldots 19 \mathrm{~m}$, meaning that in some columns, its depth doubled.

The values of the maximum main and vertical normal stresses differ on average by $2 \ldots 6 \%$, meaning the maximum stresses occurring at the soil base of the building act along the vertical axis and, therefore, influence the final settlement.

\section{Conclusions}

Assessing in general changes in the stress state of the frozen soil mass in the soil base of the building as a result of factoring thermal stresses and relation of the deformation modulus and temperature, it should be noted that there is a significant redistribution of stresses in the central part of the calculated array, there are areas of high stress concentration below the edge of the structure foundation. A zone of high non-uniformity of stresses appears, not only in terms of their numerical value, but also in the direction of action. According to the solution of the quasi-stable temperature problem, the same zone is an area of high negative temperatures, meaning the soil here is in a state close to the phase transition, and therefore, slight increase in its temperature can cause a significant change in the deformation characteristics of the soil. This way, the central part of the computational area that accommodates buried collector, area on which the outermost part of the foundations of the 
structure is supported, is potentially the most dangerous from the point of view of the occurrence of maximum permissible stresses.

Joint solution of problems of nonlinear thermal conductivity factoring in phase transitions, linear thermoelasticity and nonlinear mechanics of frozen soils in the framework of the uncoupled problem of thermomechanics is one of the most promising, effective and correct approaches to solve thermal stress-strain state calculation problems on permafrost soils, which is confirmed by field observations.

\section{References}

1. N. Belyaev, A. Ryadno, Vysshaya shkola, 328 (1978)

2. V. Melamed, Merzlotnye issledovaniya, 79-90 (1985)

3. Ya. Kronik, Reologiya gruntov i inzhenernoe merzlotovedenie, 87-94 (1982)

4. R. Demchenko, SO RAN SSSR 88, (1986)

5. E. Markov, S. Pul'nikov, A. Gerber, Fundamental'nye issledovaniya, 11-1, 100-104 (2015)

6. M. Rabinovich, Raschet termonapryazhenno-deformirovannogo sostoyaniya osnovaniy zdaniy na vechnomerzlykh zasolennykh gruntakh s uchetom peremennoy temperatury (1992)

7. N. Tsytovich, Vysshaya shkola, 287 (1973)

8. A. Plotnikov, Promyshlennoe i grazhdanskoe stroitel'stvo, 4, 62-67 (2016)

9. S. Ukhov, E. Gul'ko, M. Mnushkin, A. Vlasov, Sb.trudov/ MISI im. V.V.Kuybysheva, 118 (1973)

10. Ya. Kronik, M. Rabinovich, Ratsional'noe prirodopol'zovanie v kriolitozone. Tezisy dokladov, 85-87 (1990)

11. S. Vyalov, Vysshaya shkola, 447 (1978)

12. SP 25.13330.2012 «SNiP 2.02.04-88. Osnovaniya i fundamenty na vechnomerzlykh gruntakh» (2012)

13. V. Aksenov, Issledovanie mekhanicheskikh svoystv merzlykh gruntov kak osnovaniy sooruzheniy (na primere gruntov Arkticheskogo poberezh'ya): 23 (1980).

14. A. Karpunina, Problemy stroitel'stva v Yakutskoy ASSR, 1, 115-123 (1972)

15. E. Maksimenko, V. Ponamorev, V. Sorokin, Yu. Fedoseev, OFiMGr, 6, $23-28$ (1986)

16. Tekhnicheskiy otchet: "Otsenka merzlotno-gruntovykh usloviy i deformatsiy zdaniy g. Yakutska» OAO «YakutTISIZ» shifr 843/5549 (2010)

17. Ya. Kronik, Materialy V konf. geokriologov Rossii MGU im. Lomonosova. 1, 104-111 (2016)

18. A. Naberezhnyy, G. Kuz'min, F. Posel'skiy, Promyshlennoe i grazhdanskoe stroitel'stvo, 8, 64-69 (2011)

19. A. Naberezhnyi, G. Kuzmin, A. Savvina, IOP Conf. Ser.: Mater. Sci. Eng. 463 (3), 032035 (2018)

20. I. Syromyatnikov, I. Dorofeev, Nauka i obrazovanie, 4, 42-45 (2014)

21. I. Shishov, Osnovaniya, fundamenty i mekhanika gruntov, 4, 130-135 (2010) 